pulmonary arterial hypertension in a rat model. Int J Cardiovasc Imaging. 2010; 26:509-18.

4. Schmierer B, Hill CS. TGF $\beta$-SMAD signal transduction: molecular specificity and functional flexibility. Nat Rev Mol Cell Biol. 2007;8:970-82.

http://dx.doi.org/10.1016/j.jtcvs.2017.08.028

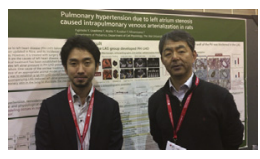

\section{ELUSIVE MECHANISMS RESPONSIBLE FOR PULMONARY HYPERTENSION}

Reply to the Editor:

We appreciate Katz and colleagues' letter to the Editor regarding our study of a rat model for pulmonary hypertension as a result of left heart disease. ${ }^{1}$ We are in complete agreement with their comments. Despite the clinical importance of pulmonary hypertension as a result of left heart disease, the pathophysiologic mechanisms of pulmonary hypertension as a result of left heart disease have not been sufficiently clarified, even in our article, as was pointed out. Katz and colleagues importantly suggested that the elevation of the left-sided filling and pulmonary venous pressures induce pulmonary congestion and the disruption of the alveolar-capillary barrier, which differs significantly from the pathophysiology of pulmonary arterial hypertension. In our original article, we established an animal model as a first step. We believe that our model should be used further in future studies, by us and by other groups, to increase understanding of this disorder.

Katz and colleagues also pointed out the critical issue regarding the measurement of pulmonary arterial pressure, which we were unable to evaluate in our study. Although we had attempted to measure pulmonary arterial pressure directly with 1.9F Rodent PV Catheters (Transonic Systems Inc, Ithaca, NY), we were unsuccessful because of bleeding. We therefore evaluated the pulmonary hypertension by assessing the ratio of the right ventricular systolic pressure to the left ventricular systolic pressure. Furthermore, as Katz and colleagues pointed out, right ventricular parameters measured by echocardiography are alternate options for evaluating pulmonary hypertension. We identified this shortcoming in the description of limitations in the Discussion section of our article, and we believe that measuring pulmonary arterial pressure in rats with a thinner catheter, such as a 1.0F Millar Mikro-Tip Pressure Catheter (Millar, Inc, Houston, Tex) will be the next challenging task for us to undertake in a future study.

In DNA microarray pathway analysis, 5 genes ( Smad4, Hipk2, Ctnnb1, Cdkn2b, and Adam9) related to the transforming growth factor $\beta$ signaling pathway were 4 times higher in the group that underwent operation. In addition, Hipk2 and Ctnnb1, which are known to be SMAD protein signal transduction factors, were also increased in the group that underwent operation (see
Author has nothing to disclose with regard to commercial support.

Supplemental Table 2 in our original article). We appreciate Katz and colleagues' indication of the importance of transforming growth factor $\beta$ and SMAD signaling pathways.

We again express our sincere appreciation to Katz and colleagues for taking the time to submit a letter to the Editor regarding our article. Such interaction and airing of other viewpoints strengthens the original submission, and we are grateful for their efforts.

\section{Yoshitaka Fujimoto, $M D^{a, b}$ Susumu Minamisawa, $M D, P h D^{a}$ Departments of ${ }^{a}$ Cell Physiology and ${ }^{b}$ Pediatrics The Jikei University School of Medicine Tokyo, Japan}

\section{Reference}

1. Fujimoto Y, Urashima T, Kawachi F, Akaike T, Kusakari Y, Ida H, et al. Pulmonary hypertension arising from left heart disease causes intrapulmonary venous arterialization in rats. J Thorac Cardiovasc Surg. 2018;155:281-2.

http://dx.doi.org/10.1016/j.jtcvs.2017.09.021

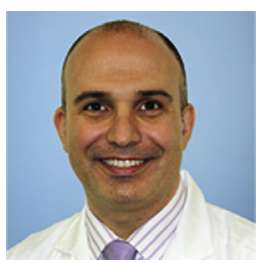

\section{NOT A CINDERELLA STORY}

\section{Reply to the Editor:}

Pulmonary hypertension that is secondary to left heart disease is one of the most common pulmonary hypertension types and also one of the most challenging to treat. ${ }^{1,2}$ This type itself is not uniform and can be related to systolic or diastolic dysfunction, valvular obstructive lesions, or pulmonary venous disease (although the last can arguably be classified under pulmonary arterial hypertension type). ${ }^{1,2}$ In addition, there are variations within this type that are associated with timing of development of the left heart lesion (eg, in utero, infancy, older) and speed of progression of the left heart disease (acute vs chronic). Because of the heterogeneity of this disorder and the relatively small yet important number of affected patients, many efforts to understand the pathophysiology of this disease and to develop innovative therapeutic strategies have relied on translational research with animal models. ${ }^{2}$

In a recent issue of the Journal, Fujimoto and colleagues ${ }^{3}$ from Japan reported their creation of an animal model of pulmonary hypertension in laboratory rats. Through a left 
Author has nothing to disclose with regard to commercial support.

thoracotomy, they used metal clips to create left atrial obstruction. Subsequently, they followed up the rats with serial echocardiograms, cardiac catheterization, and ultimately organ excision and numerous analyses of histopathology, DNA microarray, and real-time polymerase chain reaction. In comparison with a control group that underwent sham operation, Fujimoto and colleagues ${ }^{3}$ demonstrated evidence in the studied rats of increases in left atrial inflow gradient, systolic right heart pressure, diastolic left and right heart pressure, and pulmonary venous wall thickness; medial hypertrophy of the pulmonary arteries; and enhancements of transforming growth factor $\beta$ and endothelin-1 protein expressions. They concluded that this novel feasible rat model could be used to examine further the pathophysiology and potential therapeutics of pulmonary hypertension secondary to left heart disease.

Creating an animal pulmonary hypertension model is challenging. Despite the conception of dozens of the animal models in the past 2 decades, many have suffered from several drawbacks that weakened their utility in investigational research. ${ }^{2,4,5}$ In a letter to the Editor in this issue of the Journal, Katz and colleagues ${ }^{6}$ from New York highlight some of the challenges and disadvantages of those animal models in commenting on the aforementioned article by $\mathrm{Fu}-$ jimoto and colleagues ${ }^{3}$ from Japan. In their commentary, they describe in details the pathophysiologic mechanism of development of pulmonary hypertension subsequent to left atrial obstruction. That mechanism involves complex interactions among hemodynamic, histologic, and neurohormonal transformations that eventually lead to increased pulmonary vascular resistance. In addition, they highlight some of the downsides of the Fujimoto and colleagues ${ }^{3}$ study that are, similar to the other previously described animal models, inherently related to the nature of this complicated heterogeneous disease. This commentary from New York is a welcome complement to the article from Japan and underscores the need for continued pioneering research to overcome the many integral hurdles learning about this complicated disease.

One obstacle is related to the chronicity of this disease and how to simulate that in the research laboratory. Many studies have demonstrated that the structural alterations in the pulmonary vasculature subsequent to congenital heart defects are progressive, with gradual increase in severity and development of irreversibility. ${ }^{7}$ Those associated changes in the pulmonary vasculature and lung parenchyma are often most pronounced in neonates with severe obstructive lesions that started during fetal development. ${ }^{8-10}$ For example, autopsies of neonates born with hypoplastic left heart syndrome and highly restrictive or intact atrial septum have shown thickening of the pulmonary veins and dilatation of the pulmonary lymphatic vessels. ${ }^{8,9}$ Similarly, pulmonary venous arterialization and lymphangiectasia have been noted in neonates with severe forms of total anomalous pulmonary venous connection associated with individual pulmonary vein hypoplasia and stenosis. ${ }^{10}$ Consequently, future efforts should focus on how to create animal models of pulmonary hypertension secondary to left heart disease that replicate the real-life histopathologic and humoral changes while adjusting for the time factor, which is a luxury that might not realistically exist for the investigators.

Another important obstacle that Katz and colleagues ${ }^{6}$ from New York raise in their letter is the ability to matching rodent pulmonary hypertension models to human pulmonary hypertension. This is a current area of investigation, and the jury is still out as to whether we can extrapolate the findings from rats to humans. ${ }^{5}$ In the famous Cinderella folk tale, the fairy godmother uses her magic to help Cinderella attend the prince's ball and turns a pumpkin into a golden carriage and a rat into a coachman to drive that carriage. Unfortunately, this is not a Cinderella story, and rats are not humans. Research is still needed to create an ideal model for pulmonary hypertension that is applicable to humans. Only then we will have an exponential increase in our understanding of this complex disease and development of effective therapeutic strategies that would improve the poor outcomes that continue to plague children and adults affected by this difficult illness.

\section{Bahaaldin Alsoufi, $M D$ \\ Division of Cardiothoracic Surgery Emory University School of Medicine Children's Healthcare of Atlanta \\ Atlanta, $G a$}

\section{References}

1. Simonneau G, Robbins IM, Beghetti M, Channick RN, Delcroix M, Denton CP et al. Updated clinical classification of pulmonary hypertension. J Am Coll Cardiol. 2009;54(1 Suppl):S43-54.

2. Maarman G, Lecour S, Butrous G, Thienemann F, Sliwa K. A comprehensive review: the evolution of animal models in pulmonary hypertension research; are we there yet? Pulm Circ. 2013;3:739-56.

3. Fujimoto Y, Urashima T, Kawachi F, Akaike T, Kusakari Y, Ida H, et al. Pulmonary hypertension due to left heart disease causes intrapulmonary venous arterialization in rats. J Thorac Cardiovasc Surg. 2017;154:1742-53.e8.

4. Nogueira-Ferreira R, Faria-Costa G, Ferreira R, Henriques-Coelho T. Animal models for the study of pulmonary hypertension: potential and limitations. Car diol Cardiovasc Med. 2017;1:1-22.

5. Colvin KL, Yeager ME. Animal models of pulmonary hypertension: matching disease mechanisms to etiology of the human disease. J Pulm Respir Med. 2014;4:198.

6. Katz MG, Fargnoli AS, Hadri L. Pulmonary hypertension arising from left heart disease causes intrapulmonary venous arterialization in rats. $J$ Thorac Cardiovasc Surg. 2017. In press.

7. Rabinovitch M. Pathobiology of pulmonary hypertension. Annu Rev Pathol. 2007;2:369-99. 
8. Rychik J, Rome JJ, Collins MH, DeCampli WM, Spray TL. The hypoplastic left heart syndrome with intact atrial septum: atrial morphology, pulmonary vascular histopathology and outcome. J Am Coll Cardiol. 1999;34:554-60.

9. Vlahos AP, Lock JE, McElhinney DB, van der Velde ME. Hypoplastic left heart syndrome with intact or highly restrictive atrial septum: outcome after neonatal transcatheter atrial septostomy. Circulation. 2004;109:2326-30.
10. Seale AN, Uemura H, Webber SA, Partridge J, Roughton M, Ho SY, et al; British Congenital Cardiac Association. Total anomalous pulmonary venous connection: morphology and outcome from an international population-based study. Circulation. 2010;122:2718-26.

http://dx.doi.org/10.1016/j.jtcvs.2017.09.031 